\title{
The Effect of Silver Nanoparticles on Selenium Speciation Analysis in Water Sample by Flow Injection-Hydride Generation Atomic Absorption Spectrometry
}

\author{
RUTTIYA POONYAKA and SAKSIT CHANTHAI
}

Materials Chemistry Research Center, Department of Chemistry and Center of Excellence for Innovation in Chemistry, Faculty of Science, Khon Kaen University, Khon Kaen 40002, Thailand.

${ }^{*}$ Corresponding author E-mail address: sakcha2@ @ku.ac.th

http://dx.doi.org/10.13005/ojc/330315

(Received: October 18, 2016; Accepted: March 09, 2017)

\begin{abstract}
This study described selenium speciation analysis under catalytic activation and/or reduction using silver nanoparticles (AgNPs) in conjunction with common flow injection (FI)-hydride generation atomic absorption spectrometry (HGAAS). Generally, Se (IV) could be directly determined by HGAAS consisting of $0.25 \%(w / v) \mathrm{NaBH}_{4}$ in $0.1 \%(\mathrm{w} / \mathrm{v}) \mathrm{NaOH}$ as a reductant and $2 \mathrm{M} \mathrm{HCl}$ as carrier solution, while Se (VI) could not be detected. In this regard, AgNPs in which was generated in the presence of $0.25 \%(\mathrm{w} / \mathrm{v}) \mathrm{NaBH}_{4}$ was accordingly subjected in the same reducing background. Thus, the effects of the AgNPs on various factors affecting the Se analysis were investigated. From the results, it was demonstrated that the AgNPs gave insight into the catalytic activation for Se (IV) analysis, and also acted as pre-reducing agent for Se (VI) compared with $10 \%(\mathrm{w} / \mathrm{v})$ thiourea/conc. $\mathrm{HCl}$. So, the dispersed AgNPs in the HG system could serve for better sensitivity and selectivity for $\mathrm{Se}$ analysis. Furthermore, the conversion of $\mathrm{Se}(\mathrm{VI})$ to $\mathrm{Se}(\mathrm{IV})$ and its recovery study were validated using both of the pre-reducing agents. Both LOD and LOQ of the method were 0.5 and $1.0 \mu \mathrm{g} \mathrm{L}^{-1}$, respectively. The method precision (\%RSD) was ranged of 5.69 and 3.23 for an intra-day and an inter-day analysis, respectively. Therefore, the method using AgNPs was successfully applied to determine trace amounts of Se species in drinking water samples and found in the ranges of 0.03$0.10,0.12-1.0$ and $0.22-0.97 \mathrm{gmL}^{-1}$ for Se (IV), Se (VI), and total Se, respectively.
\end{abstract}

Keywords: Selenium, Silver nanoparticles, Hydride generation, Atomic absorption spectrometry, Catalytic activation, Reducing agent, Drinking water

\section{INTRODUCTION}

Selenium is essential element playing an important role in an anti-oxidation. It can also cooperate with other antioxidants in processes protecting the cells from free radicals. In such manner, it can protect a body from development of cancer, cardio vascular diseases and masculine sterility ${ }^{1-3}$. 
It participates in thyroid hormone metabolism and immune system and it inhibits virulence and slows down AIDS development. Furthermore, it can reduce the risk of spontaneous abortions ${ }^{4}$. The balanced selenium content in human food helps connecting with diabetes and also affects the prevention of asthma, and can moderate harmful effects of radiation by free radicals inhibition ${ }^{5}$. Se deficiency is connected with acceleration of senility and development of Alzheimer's disease. It also affects in a positive manner human mind and mental wellness 6 .

However, Se contents in foods and drinks are highly variable, depending on its location. Differences in toxicity occur among their various species because they follow different metabolic pathways ${ }^{7}$. Although precise feeding comparisons of the relative toxicity or nutritive activity of different Se compounds have not yet been made, it is known that selenite is more toxic than selenate ${ }^{8}$. Thus, study of the Se species in water or other sample provides better requirements of this element in the living system.

Total amounts of Se have almost reported. Few methods have been applied for selective determination of Se species in various matrixes. Chromatography coupled with various detectors has been used for separation and determination of all Se species. Few electrochemical methods can also be applied for Se speciation in biological fluids and environmental samples ${ }^{9-12}$. Either complete mineralization or conversion of $\mathrm{Se}(\mathrm{VI})$ to $\mathrm{Se}(\mathrm{IV})$ makes sample preparation more complex and increases risk of sample contamination and / or loss of Se. Spectrofluorometry has also been used for determination of Se species ${ }^{9,11}$. Organoselenium like methyl selenide can be detected by GC associated with various detection systems ${ }^{13,14}$. The most common way for Se speciation is based on hydride generation (HG) with $A A S^{11}$. Se(IV) is determined directly under $\mathrm{HG}$ process, whereas $\mathrm{Se}(\mathrm{VI})$ is determined by difference after reduction ${ }^{15}$. Their severe and systematic imprecision are almost due to the use of improper sample decomposition ${ }^{9,16}$. According to total content of Se determination, the combination of FI technique with HGAAS is widely accepted ${ }^{17-22}$. The FI-HGAAS was used for the determination of Se(IV) and $\mathrm{Se}(\mathrm{VI})$ via on-line pre-reduction of $\mathrm{Se}(\mathrm{VI})^{23}$. The method was successfully applied to the speciation analysis of both Se species.

Since only Se(IV) forms its hydride compound, $\mathrm{Se}(\mathrm{VI})$ must be completely pre-reduced to $\mathrm{Se}(\mathrm{IV})$, if the total $\mathrm{Se}$ is determined. When $\mathrm{NaBH}_{4}$ is used as a common reducing agent for the determination of Se by HGAAS, only $\mathrm{SeH}_{2}$ is formed. Pre-reducing agent is normally achieved using $\mathrm{HCl}$. The reduction time takes almost a week ${ }^{24}$. If its reduction step works at elevated temperature, it is faster ${ }^{25,26}$. The reaction time usually varies from $20-45$ $\min ^{25,27}$. However, too long heating can lead to the appearance of elemental $\mathrm{Se}^{24,28}$. The pre-reduction can also be done using co-reducing agents $27,29-31$.

Speciation is the identification and quantitative determination of different forms or phases in which a given element occurs in a given substance. In water sample, the form or phase of a given element is clearly defined ${ }^{32-34}$. The significant determination is not only the total content of the element but its speciation follows from different toxicological effects of different species in the ecosystem. For example, the inorganic $\mathrm{Se}$ is a few hundred times more toxic than its methylated forms. The speciation analysis of Se using HGAAS is based on its catalytic activation and/or reduction of hydride generation. Nevertheless, few analytical methods for the selective determination of $\mathrm{Se}$ species include ICP-MS, FI-HGAAS, or even coupled with some chromatographic techniques. However, ICP-MS approaches interference among dominant isotope ${ }^{35}$. The chromatographic ones rather give any decomposition of species and peak overlapping problems ${ }^{36}$. Hydride generation is a chemical derivatization technique in which some elements of the periodic table mentioned above form their volatile hydrides as indicated in the following reactions ${ }^{37}$ when they react with borohydride as a strong reducing agent and hydrochloric acid as carrier solution. In this technique, elements are separated from other accompanying materials in the gaseous hydrides and are introduced to the sample cell for atomization leaving the sample matrix in the liquid waste. Thus, spectral and chemical interferences can be eliminated. Therefore, the significant increase in sensitivity, by 10-100 folds, over commonly used liquid sample introduction techniques has been reported $^{38-40}$. 
Thus, this study was aimed for an ultratrace determination of inorganic Se species present in drinking water samples in order to get either higher sensitivity and/or better selectivity using the dispersed AgNPs in the presence of mild reducing condition. The method development was conducted under their catalytic activation and/or reduction of the as-prepared AgNPs solution in conjunction with common performance of FI-HGAAS.

\section{MATERIALS AND METHODS}

\section{Chemicals}

$\mathrm{Se}(\mathrm{IV})\left(1000 \mathrm{mgL}^{-1}\right), \mathrm{As}(\mathrm{III})\left(1000 \mathrm{mgL}^{-1}\right)$, and $\mathrm{Cu}$ (II) (1000 $\mathrm{mg} \mathrm{L}^{-1}$ ) as stock solutions, chromium nitrate, ferric nitrate, nickel chloride hexahydrate, sodium hydroxide, tin chloride pentahydrate and zinc nitrate were obtained from Carlo Erba (France). Hydrochloric acid (37\%, w/v) was from Lab Scan Asia (Thailand). Se(VI) and silicon dioxide (each 1000 $\mathrm{mgL}^{-1}$ ) also as stock solution were bought from Sigma Aldrich (USA). Sodium borohydride was from Lab Chem (France). Thiourea was from $\mathrm{BDH}$ (England). All aqueous solutions were prepared with deionized water (Milli Q Millipore 18.2 Mohm-cm) by Simplicity Water Purification system (Model Simplicity 185, Millipore Corporation, USA).

\section{Table 1: The operational conditions for Se determination by FI-HGAAS}

\begin{tabular}{lc}
\hline Parameter & \\
\hline Spectrometer & \\
Wavelength & $196.0 \mathrm{~nm}$ \\
Slit width & $2.0 \mathrm{~nm}$ \\
Measurement mode & Absorbance \\
Energy & 25 \\
Current of hollow cathode lamp & $16 \mathrm{~mA}$ \\
Hydride generation & \\
Carrier & $2.0 \mathrm{M} \mathrm{HCl}$ \\
Reducing agent & $0.25 \%(\mathrm{w} / \mathrm{v}) \mathrm{NaBH}$ in \\
& $0.1 \%(\mathrm{w} / \mathrm{v}) \mathrm{NaOH}$ \\
Quartz cell temperature & $900{ }^{\circ} \mathrm{C}$ \\
Sample loop volume & $500 \mu \mathrm{L}$ \\
Fill time & $10 \mathrm{~s}$ \\
Inject time & $15 \mathrm{~s}$ \\
Argon gas flow rate & $50-55 \mathrm{~mL} / \mathrm{min}$ \\
& \\
\hline
\end{tabular}

All glassware was cleaned by soaking in dilute $1 \%(\mathrm{v} / \mathrm{v}) \mathrm{HNO}_{3}$ overnight and rinsed twice with deionized water prior to use.

\section{Instrument}

Selenium measurement was made using an atomic absorption spectrometer of the PerkinElmer AAnalyst 100 (Connecticut, USA) equipped with a flow injection analysis system (FIAS-100, Perkin Elmer Instruments, USA). Argon gas was used as carrier gas for the transposition of Se hydride from the gas-liquid separator to the heated quartz tube atomizer lined with Se hollow cathode lamp (Victoria, Australia). The peristaltic pump, injection time and data acquisition were controlled through Perkin Elmer AA Win lab atomic absorption software version 3.2.

\section{Water sample}

Three brands of drinking water samples (S01, S02 and S03) were obtained from a convenient store, Khon Kaen University Foods and Service Center, Khon Kaen, Thailand. The water samples (0.6 L bottled) were instantaneously used without sample pretreatment.

\section{Operational conditions for Se analysis by FI-HGAAS}

Preparation of $100 \mu \mathrm{gL}^{-1} \mathrm{Se}(\mathrm{IV})$ or $\mathrm{Se}(\mathrm{VI})$ as working solution was made by three steps dilution from $1000 \mathrm{mgL}^{-1} \mathrm{Se}(\mathrm{IV})$ or $\mathrm{Se}(\mathrm{VI})$ stock solution. The step dilution from $10 \mathrm{mgL}^{-1}$ to $100 \mathrm{\mu gL}^{-1} \mathrm{Se}(\mathrm{IV})$ was freshly prepared prior to use. Each calibration curve of $5,10,15,20$ and $25 \mu^{-1}$ for Se(IV) and $\mathrm{Se}(\mathrm{VI})$ was separately done in $0.1 \mathrm{M} \mathrm{HCl}$ by a series dilution to mark $25-\mathrm{mL}$ volumetric flask from their working solutions. For $\mathrm{Se}(\mathrm{VI})$ analysis, the pre-reducing agent (thiourea/conc. $\mathrm{HCl}$ or AgNPs) was appropriately added and then diluted to $25 \mathrm{~mL}$ with $0.1 \mathrm{M} \mathrm{HCl}$.

For hydride generation, a common reducing agent was chosen using $0.25 \%(\mathrm{w} / \mathrm{v}) \mathrm{NaBH}_{4}$ which was prepared by dissolving $2.5 \mathrm{~g} \mathrm{NaBH}_{4}$ in $1.0 \mathrm{~L}$ of $0.1 \%(\mathrm{w} / \mathrm{v}) \mathrm{NaOH}$. This solution was freshly prepared prior to use. A $2.0 \mathrm{M} \mathrm{HCl}$ solution was used as a carrier solution. And $0.1 \mathrm{M} \mathrm{HCl}$ was used as a blank solution. The operational conditions for Se analysis using FI-HGAAS were controlled through program AA Win Lab as shown in Table 1. 
Effect of analytical matrix on Se determination

Although the suitable reducing agents can be applied for Se analysis in real samples, the matrix effect at ultra-trace level of selenium species still appears from the reducing agents used. Thus, the effect of analytical matrices on the absorbance of Se by adding each of the optimal pre-reducing agents into the standard solutions of both Se(IV) and the pre-reduced $\mathrm{Se}(\mathrm{VI})$ used as calibration curves, compared with the usual calibration curve of $\mathrm{Se}(\mathrm{IV})$ as a control were investigated under the same optimum conditions of the HGAAS. The results obtained from each of their calibration curves of both Se species either with or without the corresponding pre-reducing agents can be compared expressed as relative conversion of the two oxidation state of Se.

Concerning the pre-reduction of $\mathrm{Se}(\mathrm{VI})$, thiourea was commonly a choice of use. The concentration of thiourea in conc. $\mathrm{HCl}$ was optimized in the range of $5-20 \%(\mathrm{w} / \mathrm{v})$. The main factors affecting on the pre-reduction were carried out using

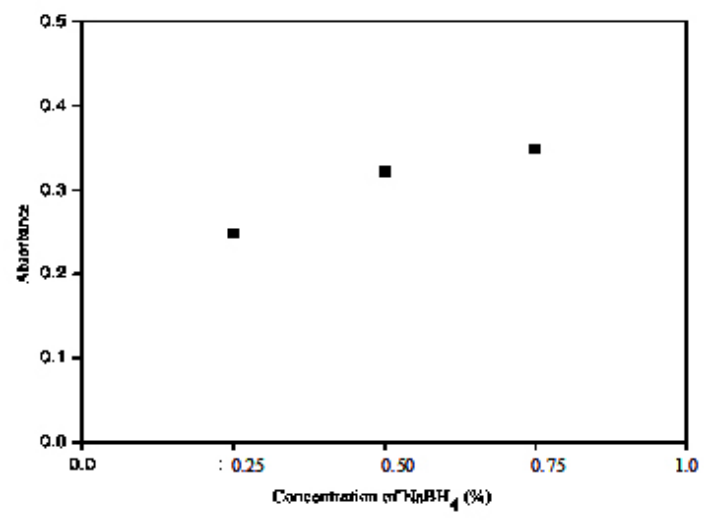

Fig. 1: Effect of concentration of $\mathrm{NaBH}_{4}$ solution on AgNPs absorption

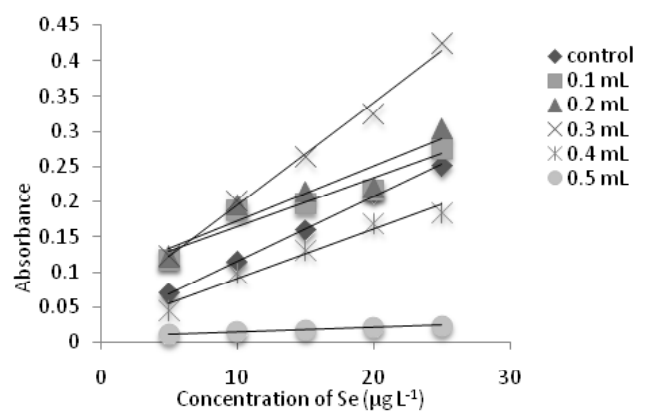

Fig. 3: Effect of the AgNPs solution on $2 \mathrm{M} \mathrm{HCl}$ as slope of $\mathrm{Se}(\mathrm{IV})$ calibration
5-25 $\mathrm{MLL}^{-1} \mathrm{Se}(\mathrm{VI})$ concentration range. By using $20 \mathrm{MgL}^{-1} \mathrm{Se}(\mathrm{VI})$, the effect of the two pre-reducing agents was comparatively studied. The effect of $\mathrm{NaBH}_{4}$ concentration was varied from 0.25 to $5.0 \%$ (w/v). The effect of AgNPs concentration was also investigated between 50 and 500 ppm.

\section{Analytical features of merit}

The analytical characteristics of the proposed method for speciation analysis were investigated under the optimum conditions. The studied parameters were linearity, limit of detection (LOD), limit of quantitation (LOQ), precision and accuracy. Linearity was obtained from calibration plot. The calibration plots were studied by analysis of standard mixtures with various concentrations ranging from 0.5 to $100.0 \mu \mathrm{gL}^{-1}$ of $\mathrm{Se}(\mathrm{IV})$. All the standard mixtures of $\mathrm{Se}(\mathrm{IV})$ and $\mathrm{Se}(\mathrm{VI})$ were prepared in the same manner. LOD and LOQ of the method were deduced based on the signal to noise ratio $(\mathrm{S} / \mathrm{N})$ of 3 and 10 , respectively.

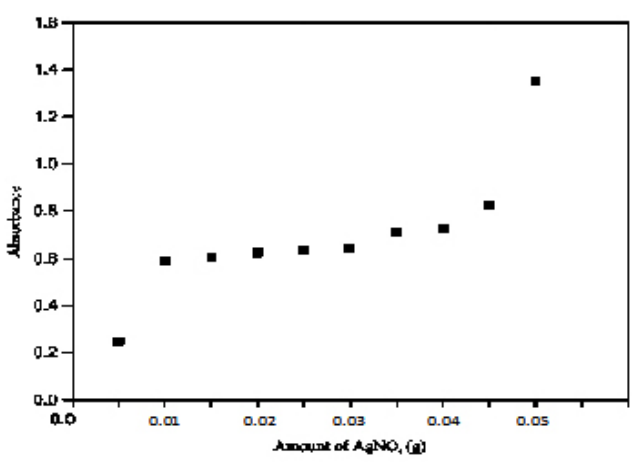

Fig. 2: Effect of amount of $\mathrm{AgNO}_{3}$ on AgNPs absorption

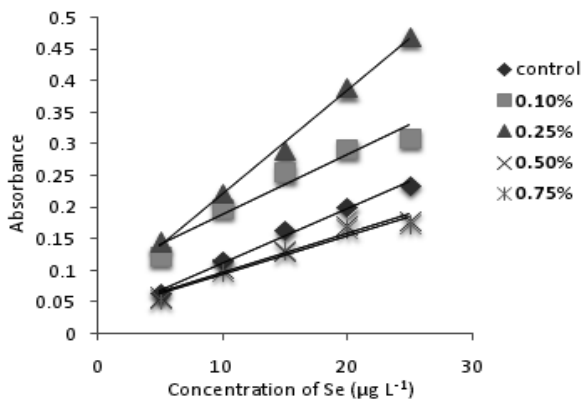

Fig. 4: Effect of borohydride (\%) in the presence of AgNPs as slope of Se(IV) 
The precision of the proposed method was evaluated in terms of reproducibility and repeatability of the calibration slope. The repeatability (intra-day precision) was achieved by replicating measurements of the calibration slop within a day $(n=10)$. Whereas, the reproducibility (inter-day precision) was calculated from the experiments carried out in ten consecutive days $(n=10)$. The accuracy of the method was expressed in terms of recovery. The recovery was studied by spiking a known concentration of standard into samples before analysis in nine replicates. To test the recovery study of real sample in order to restrict other matrix effects of the water samples, each of the suitable pre-reducing agents was chosen and applied by spiking each standard solution of $\mathrm{Se}(\mathrm{IV})$ and $\mathrm{Se}(\mathrm{VI})$ at $20 \mathrm{\mu gL}^{-1}$, and both Se species at $20 \mathrm{\mu gL}^{-1}$ into the drinking water sample S01as a model solution.

\section{Real sample analysis}

The Se(IV) content in drinking water sample (25 $\mathrm{mL}$ ) was directly determined by FI-HGAAS. While the $\mathrm{Se}(\mathrm{VI})$ in this sample was completely pre-reduced to get $\mathrm{Se}(\mathrm{IV})$ by using $10 \%(\mathrm{w} / \mathrm{v})$ thiourea/conc. $\mathrm{HCl}$ $(2 \mathrm{~mL})$ in comparison with 100 ppm AgNPs (1 mL) as catalytic activation and/or reduction prior to the measurement. At first, $2 \mathrm{~mL}$ of $10 \%(\mathrm{w} / \mathrm{v})$ thiourea/ conc. $\mathrm{HCl}$ was added into $25 \mathrm{~mL}$ of the water sample and made up the final volume of $50 \mathrm{~mL}$ with $0.1 \mathrm{M}$ $\mathrm{HCl}$ prior to analysis by FI-HGAAS. Alternatively, this pre-reducing agent was also added into the water sample in the presence of $20 \mathrm{ngL}^{-1} \mathrm{Se}(\mathrm{IV})$ or in the presence of $20 \mathrm{ngL}^{-1} \mathrm{Se}(\mathrm{VI})$. For comparison, $1 \mathrm{~mL}$ of $100 \mathrm{mgL}^{-1}$ AgNPssolution was added into $25 \mathrm{~mL}$ of the water sample. Then, this AgNPs solution was also added into the water sample in the presence of $20 \mathrm{ng} \mathrm{L}^{-1} \mathrm{Se}(\mathrm{IV})$ or in the presence of $20 \mathrm{ng} \mathrm{L}^{-1}$ $\mathrm{Se}(\mathrm{VI})$ prior to analysis.

\section{RESULTS AND DISCUSSIONS}

\section{Reducing back ground of HG and AgNPs solution}

In this study, it was aimed to find a novel point of views for method development of selenium analysis under catalytic activation and/or reduction of silver nanoparticles (AgNPs) using FI-HGAAS. In fact, $\mathrm{Se}(\mathrm{IV})$ in water sample could be directly determined by HGAAS. Practically, in this study the on-line $\mathrm{HG}$ of $\mathrm{Se}$ (IV) was done under mild reducing conditions consisting of $2 \mathrm{M} \mathrm{HCl}$ as a carrier solution and $0.25 \%(\mathrm{w} / \mathrm{v}) \mathrm{NaBH}_{4}$ in $0.1 \%(\mathrm{w} / \mathrm{v}) \mathrm{NaOH}$ as a common reducing agent. Thus, trace amount of dispersed AgNPs in the reducing background might take action roles on either as heterogeneous catalystor as reducing agent for higher detection sensitivity.

Firstly, AgNPs at the concentration of 500 $\mathrm{mgL}^{-1}$ were obtained by an addition of silver nitrate

Table 2: Comparing between conversion (\%) and recovery $(\%)^{\mathrm{b}}$ using two kinds of the pre-reducing agents with respect to their calibration curves of both $\mathrm{Se}(\mathrm{IV})$ and $\mathrm{Se}(\mathrm{VI})$ in the presence of each of the pre-reducing agents used

\begin{tabular}{|c|c|c|c|c|c|c|c|c|}
\hline \multirow{3}{*}{$\begin{array}{l}\text { Calibration } \\
\text { curve/ } \\
\text { Pre-reducing } \\
\text { agent }\end{array}$} & \multicolumn{4}{|c|}{ Se(IV)/reducing agent } & \multicolumn{4}{|c|}{$\mathrm{Se}(\mathrm{VI}) /$ reducing agent } \\
\hline & & \multicolumn{2}{|c|}{$\begin{array}{l}10 \%(w / v) \text { thiourea } \\
\text { /conc. } \mathrm{HCl}\end{array}$} & AgNPs & \multicolumn{2}{|c|}{$\begin{array}{c}10 \%(w / v) \text { thiourea } \\
\text { /conc. } \mathrm{HCl}\end{array}$} & \multicolumn{2}{|l|}{ AgNPs } \\
\hline & Conversion & Recovery & Conversion & Recovery & Conversion & Recovery & Conversion & Recovery \\
\hline $\begin{array}{l}\mathrm{Se}(\mathrm{IV}) / \\
\text { control }^{\mathrm{c}}\end{array}$ & 84.23 & 103.40 & 98.68 & 99.62 & 95.54 & 115.3 & 90.59 & 125.7 \\
\hline $\begin{array}{l}\text { Se(IV)/reducing } \\
\text { agent }\end{array}$ & 98.56 & 105.9 & 96.93 & 106.7 & 112.2 & 108.5 & 115.2 & 123.1 \\
\hline $\begin{array}{l}\text { Se(VI)/reducing } \\
\text { agent }\end{array}$ & 103.8 & 105.8 & 100.00 & 102.4 & 104.8 & 101.6 & 106.8 & 103.6 \\
\hline
\end{tabular}

aConversion refers for conversion of the standard solution of $\mathrm{Se}(\mathrm{VI})$ to $\mathrm{Se}(\mathrm{IV})$.

${ }^{\mathrm{b}}$ Recovery refers to the sample spiked with each of the standard solution of $10 \mu \mathrm{gL}^{-1} \mathrm{Se}(\mathrm{IV})$ or $\mathrm{Se}(\mathrm{VI})$.

'Standard solution of Se(IV) without the pre-reducing agent. 
solution drop wise into chilled solution of sodium borohydride. Two-fold molar excess of boro hydride to $\mathrm{Ag}^{+}$was used. The reaction solution turned yellow representing the characteristics of the spherical AgNPs. The concentration of $\mathrm{NaBH}_{4}$ had a significant effect on the absorbance of the particles. An increase in the absorbance of AgNPs with various $\mathrm{NaBH}_{4}$ concentrations was observed as shown in Figure 1.

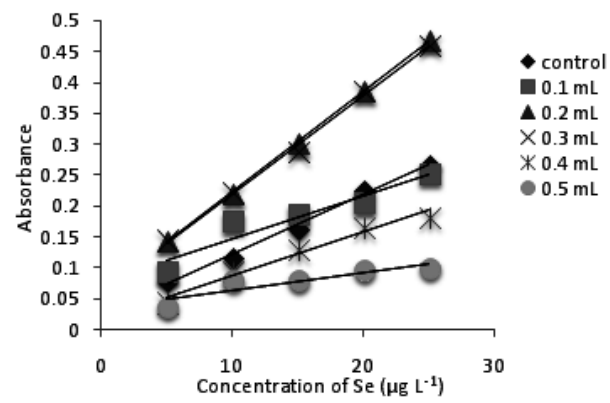

Fig. 5: Effect of the AgNPs solution on the series solution of $\mathrm{Se}(\mathrm{IV})$ calibration

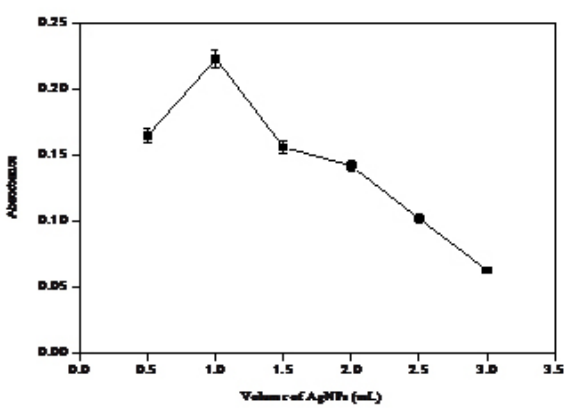

Fig. 6: Effect of the AgNPs in the presence of $0.5 \%(w / v) \mathrm{NaBH}_{4}$ on $\mathrm{Se}(\mathrm{VI})$ solution
The absorbance of AgNPs increased considerably with an increasing the boro hydride concentrations from 0.25 to $0.75 \%(w / v)$. However, the minimum concentration of $0.25 \%(\mathrm{w} / \mathrm{v}) \mathrm{NaBH}_{4}$ was chosen for background reduction in further experiments. On the other hand, the amount of $\mathrm{AgNO}_{3}$ could also be affected on the production of AgNPs as well, if there was no complete reduction by the borohydride. Figure 2 shows the increase in the absorbance of AgNPs with an increasing of $\mathrm{Ag}^{+}$. The absorbance increased markedly with an increase in two concentration ranges; initial range between 0.005 and $0.01 \mathrm{~g}$ and the other one between 0.04 and $0.05 \mathrm{~g}$. Thus, the minimum amount of $0.01 \mathrm{~g} \mathrm{AgNO}_{3}$ was used, giving the maximum wavelength at 355 $\mathrm{nm}$ of the AgNPs solution.

\section{Effect of the AgNPs on the FI-HGAAS system Effect of the AgNPs on the carrier solution}

Using $2 \mathrm{M} \mathrm{HCl}$ as a carrier solution in the FI-HGAAS, the addition of 100 ppm AgNPs solution with various volumes from $0.1-0.5 \mathrm{~mL}$ into the carrier solution resulted in the differences in their Se calibration curves ranging of 5-25 $\mathrm{M} \mathrm{L} \mathrm{L}^{-1}$. It was found that $0.3 \mathrm{~mL}$ of the AgNPs solution gave higher sensitivity (about 1.6 folds) as the observed slope of the regression line: $y=0.0146 x+0.0496$ with $\mathrm{R}^{2}=0.9914$ compared with that of the control one: $\mathrm{y}$ $=0.0092 x+0.0225$ with $R^{2}=0.9988$ (Fig. 3) .

\section{Effect of the AgNPs on the borohydride concentration}

Addition of $0.3 \mathrm{~mL}$ of AgNPs solution (100 ppm) into the $\mathrm{NaBH}_{4}$ solution with various

Table 3: Both an inter-day and an intra-day precision of the proposed method

\begin{tabular}{lrrrr}
\hline & $\begin{array}{r}\text { Inter-day }(\mathbf{n}=\mathbf{1 0}) \\
\text { Linear equation }\end{array}$ & RSD (\%) & $\begin{array}{r}\text { Intra-day }(\mathbf{n}=10) \\
\text { Linear equation }\end{array}$ & RSD (\%) \\
\hline 1 & $y=0.0092 x-0.0113$ & $y=0.0092 x+0.0278$ & \\
2 & $y=0.0088 x+0.0355$ & $y=0.0093 x-0.0198$ & \\
3 & $y=0.0091 x+0.0286$ & $y=0.0105 x+0.0041$ & \\
4 & $y=0.0105 x+0.0045$ & 3.23 & $y=0.0100 x+0.0077$ & \\
5 & $y=0.0090 x+0.0373$ & $y=0.0089 x+0.0375$ & \\
6 & $y=0.0093 x+0.0272$ & $y=0.0095 x+0.0232$ & \\
7 & $y=0.0105 x+0.0029$ & $y=0.0092 x+0.0292$ & \\
8 & $y=0.0083 x+0.0309$ & $y=0.0084 x+0.0303$ & \\
9 & $y=0.0090 x+0.0193$ & $y=0.0089 x+0.0218$ & \\
10 & $y=0.0092 x+0.0292$ & $y=0.0097 x-0.0209$ & \\
\hline
\end{tabular}


concentrations of $0.1-0.75 \%(w / v)$ also affected the slope of the $\mathrm{Se}(\mathrm{IV})$ calibration curves. It was found that $0.25 \%(w / v) \mathrm{NaBH}_{4}$ solution in the presence of AgNPs solution gave higher sensitivity (about 1.9 folds) as the observed slope of the linear regression line: $y=0.0163 x+0.0567$ with $R^{2}=0.9967$ compared with that of the control: $y=0.0085 x+0.0263$ with $R^{2}$ $=0.9908$ as shown in Figure 4 .

\section{Effect of the AgNPs on series solution of Se(IV) calibration}

The addition of $100 \mathrm{ppm}$ AgNPs solution with various volumes of $0.1-0.5 \mathrm{~mL}$ into the series standard solution of Se(IV) for construction of the calibration curve. It was found that $0.2 \mathrm{~mL}$ of the AgNPs gave higher sensitivity (about 1.7 folds) as $y=0.0163 x+0.0591$ with $R^{2}=0.9996$ compared

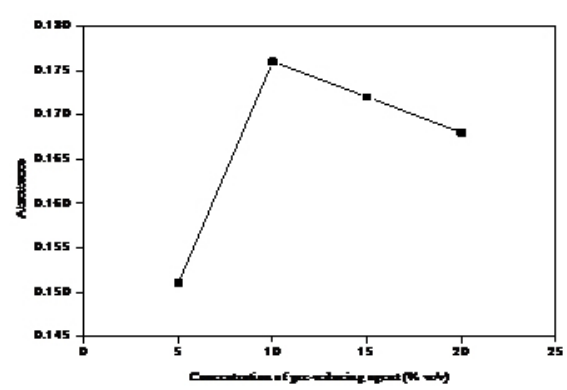

Fig. 7: Effect of thiourea (\%)/conc. $\mathrm{HCl}$ as the pre-reducing agent for $\mathrm{Se}(\mathrm{VI})$ solution

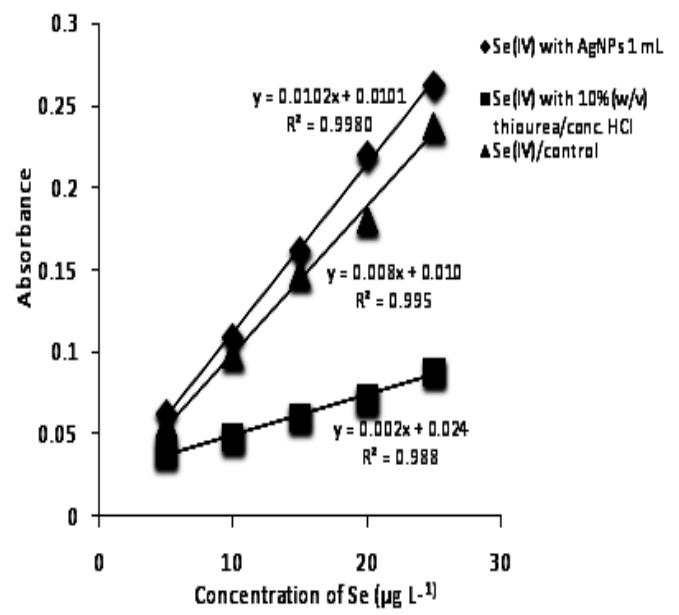

Fig. 8: The calibration curves for standard solution of $\mathrm{Se}(\mathrm{IV})$ in the presence or in the absence (control) of $10 \%$ (w/v) thiourea/conc. $\mathrm{HCl}$ and the AgNPs solution (100 ppm) with that of the control: $y=0.0098 x+0.0236$ with $\mathrm{R}^{2}=0.9933$ as shown in Figure 5 .

\section{Effect of the AgNPs on the pre-reduction of $\mathrm{Se}(\mathrm{VI})$ solution}

The AgNPs (100 ppm) was generated in the presence of $0.5 \%(\mathrm{w} / \mathrm{v}) \mathrm{NaBH}_{4}$ and then was added with various volumes of $0.5-3.0 \mathrm{~mL}$ into the $\mathrm{Se}(\mathrm{VI})$ solution. It was found that the use of $1.0 \mathrm{~mL}$ of the AgNPs solution gave the highest absorbance (Fig. 6).

Effect of thiourea concentration/conc. $\mathrm{HCl}$ for $\mathrm{Se}(\mathrm{VI})$ determination

The concentration of thiourea used as a common pre-reducing agent was investigated in the range of $5.0-20 \%(\mathrm{w} / \mathrm{v})$ with fixed $2 \mathrm{~mL}$ of conc. $\mathrm{HCl}$, and diluted to $25 \mathrm{~mL}$ with deionized water prior to analysis by FI-HGAAS. As shown in Figure 7, it was found that $10 \%(\mathrm{w} / \mathrm{v})$ thiourea/conc. $\mathrm{HCl}$ gave the highest absorbance of $\mathrm{Se}(\mathrm{VI})$ among other conditions trialed in this experiment.

\section{Selenium speciation analysis}

Effects of thiourea/conc. $\mathrm{HCl}$ and AgNPs on $\mathrm{Se}$ species

The calibration curves of $\mathrm{Se}(\mathrm{IV})$ standard solution in the presence of either $10 \%(\mathrm{w} / \mathrm{v})$ thiourea/ conc. $\mathrm{HCl}$ or the AgNPs solution (100 ppm, $1 \mathrm{~mL}$ ) compared with that of $\mathrm{Se}(\mathrm{IV})$ standard solution in the absence of the pre-reducing agent as a control, were

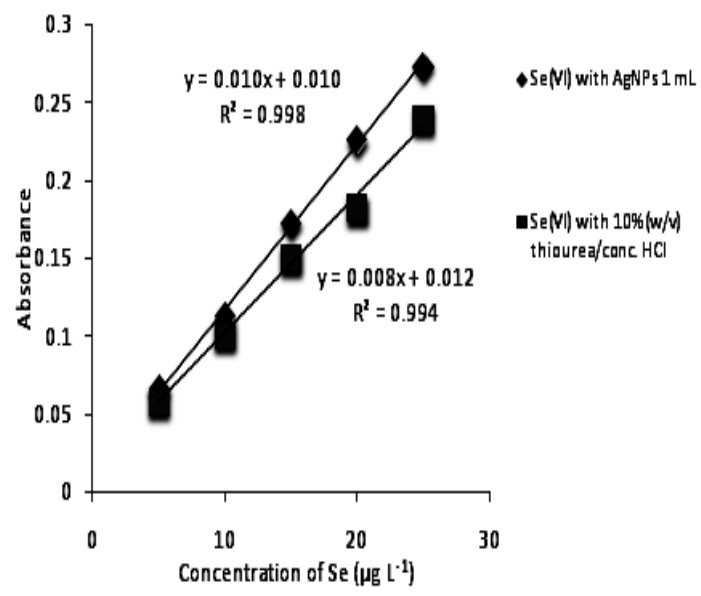

Fig. 9: The calibration curves for standard solution of $\mathrm{Se}(\mathrm{VI})$ in the presence or in the absence (control) of $10 \%(w / v)$ thiourea/conc. $\mathrm{HCl}$ and the AgNPs solution (100 ppm) 
constructed with their linear equations as shown in Figure 8. Differences in sensitivity depicted as its slope of their calibration curves were rather clear in particular using AgNPs about 5 folds with respect to the control, indicating that there is no matrix effect for Se(IV) analysis. In addition, it was evident that the catalytic activation of the dispersed AgNPs on the calibration curve of $\mathrm{Se}(\mathrm{IV})$ was predominantly remark. While the sensitivity affected using $10 \%(\mathrm{w} / \mathrm{v})$ thiourea/conc. $\mathrm{HCl}$ was much more pronounced.

In the same manner for $\mathrm{Se}(\mathrm{VI})$ standard solution with both of the pre-reducing agents, it was found the sensitivity of $\mathrm{Se}(\mathrm{VI})$ calibration curve $\left(y=0.008 x+0.012, R^{2}=0.994\right)$ in the presence of $10 \%(\mathrm{w} / \mathrm{v})$ thiourea/conc. $\mathrm{HCl}$ (Fig.9) was not so much different with that of $\mathrm{Se}(\mathrm{IV})$ solution $\left(y=0.002 x+0.024, R^{2}=0.988\right)$ (Fig. 8). While $\mathrm{Se}(\mathrm{VI})$ solution $\left(\mathrm{y}=0.010 \mathrm{x}+0.010, \mathrm{R}^{2}=0.998\right)$ in the presence of the AgNPs gave higher sensitivity about 1.25 folds comparing with that of $\mathrm{Se}$ (IV) solution $\left(y=0.008 x+0.010, R^{2}=0.995\right)$ (Fig. 8), even it

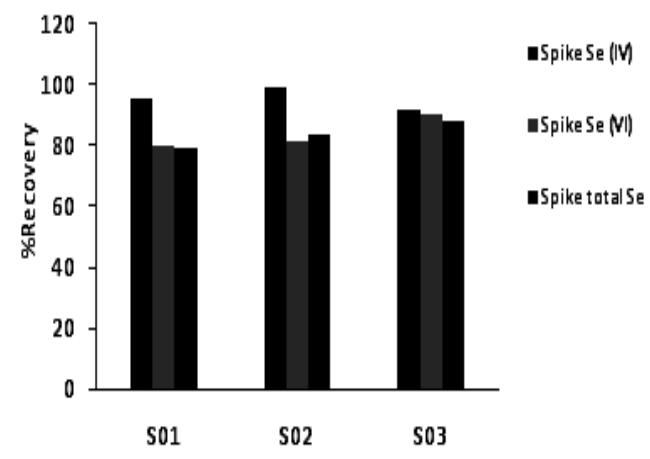

Fig. 10: Recovery (\%) of water samples spiked with $10 \mu \mathrm{g} \mathrm{L}^{-1}$ of $\mathrm{Se}$ (IV) or Se(VI) and $20 \mathrm{\mu g} \mathrm{L}^{-1}$ of both Se species (total Se) followed by $10 \%$ (w/v) thiourea/conc. $\mathrm{HCl}$ was nearly comparable to that $(y=0.008 x+0.012$, $\left.\mathrm{R}^{2}=0.994\right)$ of using $10 \%(\mathrm{w} / \mathrm{v})$ thiourea/conc. $\mathrm{HCl}$ (Fig. 9). It is, therefore, demonstrated that the AgNPs present distinct roles as plausible catalytic activation and pre-reduction potential instead of using only as the common pre-reducing agent. Actually, their slopes of the two pre-reduction systems of $\mathrm{Se}(\mathrm{VI})$ also gave not much difference in the matrix effect, if they were used as the standard working solution which could be tested for the efficiency of their reduction/conversion system. All of these prereducing agents can be used to completely convert $\mathrm{Se}(\mathrm{VI})$ to $\mathrm{Se}(\mathrm{IV})$ for the inorganic Se determination. Alternatively, the addition of the AgNPs into the $\mathrm{Se}(\mathrm{VI})$ solution led clearly to increase its sensitivity and selectivity for Se speciation analysis.

\section{Relative conversion of Se species and their recovery study}

For comparing between the percentage conversion and their recovery study of Se(IV) and $\mathrm{Se}(\mathrm{VI})$ using the two pre-reducing systems, they were determined by their different calibration curves as shown in Table 2. The results indicated that the prereducing agents including $10 \%(\mathrm{w} / \mathrm{v})$ thiourea/conc. $\mathrm{HCl}$ and the AgNPs solution show similar trends in both relative conversion and its recovery when using the same calibration curve. Therefore, both of the pre-reducing agents should be suitable to reduce $\mathrm{Se}(\mathrm{VI})$ to $\mathrm{Se}(\mathrm{IV})$. Then, two optimal pre-reducing agents were chosen. Both conversion (96.9-103.8\%) and recovery (102.4-106.7\%) are found in similar trends when using $\mathrm{Se}(\mathrm{IV})$ as control and $\mathrm{Se}(\mathrm{IV})$ in the presence of the pre-reducing agents as their calibration curves.

The satisfied trends in both conversion (104.8-115.2\%) and its recovery (101.6-123.1\%)

Table 4: Comparative study of recovery of $\mathrm{Se}(\mathrm{VI}), \mathrm{Se}(\mathrm{VI})$ and total Se in water sample (S01) using the pre-reduction agents after spiking their Se species

\begin{tabular}{lccc}
\hline & \multicolumn{3}{c}{$\operatorname{Recovery}(\%) \pm \operatorname{SD}(\boldsymbol{n}=\mathbf{3})$} \\
\cline { 2 - 4 } Pre-reducing agent & $\mathrm{Se}(\mathrm{IV})^{\mathrm{a}}$ & $\mathrm{Se}(\mathrm{VI})^{\mathrm{a}}$ & $\mathrm{Se}(\mathrm{IV}) / \mathrm{Se}(\mathrm{VI})^{\mathrm{b}}$ \\
\hline $10 \%(\mathrm{w} / \mathrm{v})$ Thiourea/conc. HCl & $85.57 \pm 7.53$ & $103.2 \pm 5.21$ & $84.85 \pm 6.32$ \\
100 ppm AgNPs solution & $83.48 \pm 3.36$ & $98.90 \pm 3.56$ & $83.10 \pm 4.23$ \\
\hline
\end{tabular}

asample spiked with each of $10 \mu \mathrm{g} \mathrm{L}^{-1} \mathrm{Se}(\mathrm{IV})$ or $\mathrm{Se}(\mathrm{VI})$

bsample spiked with $20 \mu \mathrm{g} \mathrm{L}^{-1}$ of both Se species 
were also found for $\mathrm{Se}(\mathrm{VI})$ as well. Consequently, both of them can be used as the calibration curve for the determination of inorganic Se species and total Se in water samples.

\section{Analytical performance characteristics}

The analytical performance of the FIHGAAS system was evaluated under the optimum conditions including calibration curve, both LOD and $L O Q$, precision and accuracy (recovery) were investigated.

The calibration curve was constructed between 0.1 and $50.0 \mu \mathrm{g} \mathrm{L}^{-1} \mathrm{Se}(\mathrm{IV})$ standard solution, but the linearity was maintained up to $100.0 \mu \mathrm{g} \mathrm{L}^{-1}$ $(y=0.006 x+0.015)$ with a correlation coefficient $\left(R^{2}\right)$ greater than 0.9961 . The LOD and LOQ calculated as three and ten times standard deviation of absorbance of 10 reagent blanks divided by the standard calibration slope of Se(IV) were found to be $0.5 \mu \mathrm{g} \mathrm{L}^{-1}$ and $1 \mu \mathrm{g} \mathrm{L}^{-1}$, respectively. This LOD was found less than those previously reported ${ }^{41,42}$.

Reproducibility (inter-day precision) and repeatability (intra-day precision) were investigated in terms of relative standard deviation (\%RSD, $n=10$ ) as shown in Table 3. The precision of the calibration curve of $\mathrm{Se}(\mathrm{VI})$ solution between 5

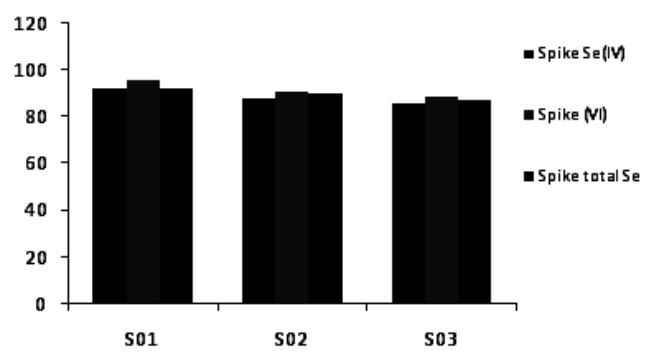

Fig. 11: Recovery (\%) of water samples spiked with $10 \mu \mathrm{g} \mathrm{L}^{-1}$ of $\mathrm{Se}(\mathrm{IV})$ or $\mathrm{Se}(\mathrm{VI})$ and $20 \mu \mathrm{g}$ $\mathrm{L}^{-1}$ of both Se species (total Se) followed by AgNPs

Table 5: The contents ( $\mu \mathrm{g} \mathrm{mL}^{-1}$ ) of $\mathrm{Se}(\mathrm{IV}), \mathrm{Se}(\mathrm{VI})$ and total $\mathrm{Se}$ in water samples

\begin{tabular}{lccc}
\hline Water sample & $\mathrm{Se}(\mathrm{IV})$ & $\mathrm{Se}(\mathrm{VI})$ & Total Se \\
\hline S01 & 0.086 & 0.996 & 0.973 \\
S02 & 0.034 & 0.123 & 0.222 \\
S03 & 0.099 & 0.242 & 0.215 \\
\hline
\end{tabular}

and $25 \mu \mathrm{g} \mathrm{L}^{-1}$ was in the acceptable ranges of RSD between $3.23 \%$ and $5.69 \%$ for an inter-day and an intra-day analysis, respectively. The results gave rather higher precision for each of the calibration curve for Se analysis.

The accuracy of the proposed method was certainly concerned in terms of recovery. The recovery study of $\mathrm{Se}(\mathrm{IV}), \mathrm{Se}(\mathrm{VI})$ and both Se species using the two pre-reducing agents was shown in Table 4. The average recoveries (\%) of Se(IV), Se(VI) and total Se in the water sample (S01) using $10 \%$ (v/v) thiourea/conc. $\mathrm{HCl}$ were found to be 85.57 , 103.2 and 84.85 , respectively. The recoveries (\%) of $\mathrm{Se}(\mathrm{IV}), \mathrm{Se}(\mathrm{VI})$ and total Se using 100 ppm AgNPs found in that water sample were also ranged of $83.48,98.90$ and 83.10 , respectively. The recoveries of the Se species in three brands of drinking water samples (S01, S02 and S03) followed by the prereduction with $10 \%(\mathrm{v} / \mathrm{v})$ thiourea/conc. $\mathrm{HCl}$ were shown in Figure 10. Their average recoveries (\%) of $\mathrm{Se}(\mathrm{IV}), \mathrm{Se}(\mathrm{VI})$ and total Se in the drinking water samples were ranged between 92.0-98.9, 79.990.2 and 78.9-88.3, respectively. And from Figure 11 , the average recoveries (\%) followed by using the AgNPs of Se(IV), Se(VI) and total Se found in these water samples were also ranged in between 92.95.9, 87.9-90.5 and 83.6-88.5, respectively. This is demonstrated that using the AgNPs instead of any common pre-reducing agent for Se speciation can be an effective work done as well.

\section{Analysis of real samples}

Generally, the residual organic matter could interfere the hydride generation. Table 5 shows the amounts of Se determination in three brands of drinking water (S01, S02 and S03). The concentration of $\mathrm{Se}(\mathrm{VI})$ was calculated as the difference between total Se and Se(IV). These samples gave at trace Se contents $\left(\mu \mathrm{g} \mathrm{mL}^{-1}\right)$ ranging from 0.03-0.10, 0.12-1.0 and 0.22-0.97 for Se(IV), $\mathrm{Se}(\mathrm{VI})$, and total Se, respectively. Concerning the inorganic Se species in these water samples, the $\mathrm{Se}(\mathrm{VI})$ is found in higher contents than the $\mathrm{Se}(\mathrm{VI})$.

\section{Effect of some interfering ions}

An interference of some diverse ions was also examined in triplicate. Several other ions were added at the concentrations of $1 \mathrm{mg} \mathrm{L}^{-1}$ or $10 \mathrm{mg}$ $\mathrm{L}^{-1}$ into $0.1 \mathrm{mg} \mathrm{L}^{-1}$ of $\mathrm{Se}(\mathrm{IV})$ standard solution. Their 
Table 6: The interference study of some diverse ions for Se species in the water sample

\begin{tabular}{|c|c|c|c|}
\hline \multirow[t]{3}{*}{ Ion } & \multirow{3}{*}{$\mathrm{Se}(\mathrm{IV})$} & \multicolumn{2}{|c|}{ Recovery (\%) } \\
\hline & & \multicolumn{2}{|l|}{$\mathrm{Se}(\mathrm{VI})$} \\
\hline & & $\begin{array}{c}10 \%(v / v) \text { Thiourea/ } \\
\text { conc. HCl }\end{array}$ & $\begin{array}{c}100 \text { ppm } \\
\text { AgNPs }\end{array}$ \\
\hline $\mathrm{Zn}(\mathrm{II})$ & 103.5 & 103.8 & 105.2 \\
\hline $\mathrm{Cr}(\mathrm{III})$ & 101.4 & 109.3 & 100.7 \\
\hline $\mathrm{Ni}(\mathrm{II})$ & 102.5 & 102.2 & 98.30 \\
\hline $\mathrm{Sn}(\mathrm{II})$ & 101.5 & 98.80 & 95.60 \\
\hline $\mathrm{Sb}(\mathrm{III})$ & 102.1 & 99.60 & 97.50 \\
\hline $\mathrm{Si}(\mathrm{II})$ & 105.8 & 101.5 & 101.8 \\
\hline $\mathrm{Cu}(\mathrm{II})$ & 53.20 & 83.40 & 86.45 \\
\hline As (III) & 86.90 & 91.54 & 96.99 \\
\hline $\mathrm{Fe}(\mathrm{II})$ & 102.6 & 97.30 & 94.60 \\
\hline $\mathrm{Pb}(\mathrm{II})$ & 95.00 & 99.00 & 96.20 \\
\hline
\end{tabular}

percentage relative absorbance is shown in Table 6. While the effects of $\mathrm{Zn}(\mathrm{II}), \mathrm{Cr}(\mathrm{III})$ and $\mathrm{Fe}(\mathrm{II})$ were negligible, serious negative interferences were observed from $\mathrm{Cu}(\mathrm{II})$ and $\mathrm{As}(\mathrm{III})$. This negative interference probably occurred because $\mathrm{Cu}(\mathrm{II})$ reacted with the produced $\mathrm{H}_{2} \mathrm{Se}$ to form CuSe ${ }^{43,44}$. Fortunately, there was no interference from $0.1 \mathrm{mg}$ $\mathrm{L}^{-1} \mathrm{Cu}(\mathrm{II})$, and the contents of $\mathrm{Cu}(\mathrm{II})$ found in waste samples were about $0.001 \mathrm{mg} \mathrm{L}^{-1}$. Therefore, the effects of $\mathrm{Cu}(\mathrm{II})$ will be negligible for these drinking water samples as well. Testing of As(III) was also done and their As contents found in these water samples were less than $0.001 \mathrm{mg} \mathrm{L}^{-1}$, and the interference from $\mathrm{As}$ (III) at this level was neither negligible.

\section{CONCLUSION}

In this study, the inorganic selenium speciation under catalytic activation and/or reduction using silver nano particles (AgNPs) in association with FI-HGAAS was developed for the first time. The AgNPs were freshly prepared by a dropwise addition of silver nitrate into chilled aqueous solution of twofold molar excess of sodium borohydride, giving the pale yellow solution with an intense maximum absorption at $335 \mathrm{~nm}$. By using AgNPs in the presence or the absence of borohydride, the results demonstrated that they acted not only as a catalytic activation for $\mathrm{Se}$ (IV) but also as a pre-reducing agent for $\mathrm{Se}(\mathrm{VI})$ analysis. Therefore, the dispersed AgNPs could enhance in both selectivity and sensitivity for ultra-trace determination of selenium in water samples.

\section{ACKNOWLEDGEMENTS}

The authors thank the Higher Education Research Promotion and National Research University Project of Thailand, Office of the Higher Education Commission, through the Food and Functional Food Research Cluster of Khon Kaen University, Materials Chemistry Research Center, Department of Chemistry and Center of Excellence for Innovation in Chemistry (PERCH-CIC), Thailand for financial support.

\section{REFERENCES}

1. Giovanelli, G.; Paradiso, A.J. Agric. Food Chem. 2002,50, 7277-7281

2. Miteva, E.; Maneva, S.; Hristova, D.; Bojinova, P.J. Phytopathol. 2001, 149, 179-184

3. Foy, C.D.; Chaney, R.L.; White, M.C. Plant Physiol. 1978, 29,511-566

4. Lombi, E.; Zhao, F.J.; Fuhrmann, M.; Ma, L. Q.; McGrath, S.P.New Phytolog. 2002, 156, 195-203

5. Onyegbule, A.F.;Okorie, D.E.; Onyegbule, C.E. Inter. J. Toxicol. Pharmacolog. Res. 2010, 2

6. Underwood, E.I. Selenium, in: Trace Elements in Human and Animal Nutrition. New York:
Academic Press, 1977

7. Petropoulou, M.O.; Michalke, B.; Kavouras, D.; Schramel, P. Anal. Chim. Acta. 2003,478, 219-227

8. Alaejos, M.; Romero, C. Chem. Rev. 1995, 95, 227-257

9. Raptis, S.E.; Kaiser, G.; Tolg, G.Fresenius' Zeitschriftfür Anal. Chem.1983, 316, 105-123

10. Mufioz, R.; Donard, O.; Camara, C.; Ouevauviller, P. Anal. Chim. Acta.1994, 286, 357-370

11. Bryce, D.W.; Izquierdo, A.; Luque de Castro, 
M.D. Anal. Chim. Acta.1995, 308,96-101

12. Jiang, S.; Robberecht, H.; Adams, F.; Van der Berghe, D. Toxicol. Envir. Chem.1983, 6, 191-201

13. Olsen, K.B.; Sklarew, D.S.; Evans, J.C.Spectrochim. Acta.1985, 40, 357-365

14. Verlinden, M.; Deelstra, H.A.; Adrianensses, E. Talanta 1981, 28, 637-646

15. Welz, B.; Stauss, P.Spectrochim. Acta Part B.1993, 48, 951-976

16. Chan, C.C. Anal. Chem. 1985, 57, 14821485

17. Fang, Z.; Xu, S.; Wang, X.; Zhang, S. Anal. Chim. Acta1986, 179, 169-179

18. Ikeda, M. Anal. Chim. Acta. 1985, 170, 217224

19. Pyen, G.S.; Browner, R.F.Appl. Spectro. 1988, 42, 508-512

20. Cobo, M.G.; Palacios, M.A.; Chmara, C. Anal. Chim. Acta.1993, 283, 386-392

21. Pyrznska, K.; Siepak, J.; Kowalczuk, Z. Polish J.Envir. Stud.1999, 8, 183-187

22. Cobo, M.G.; Palacios, M.A.; Camara, C.; Reis, F. Anal. Chim. Acta. 1994, 286, 371-379

23. Pyrzynska, K. Anal. Chim. Acta. 1998, 363, 141-146

24. Brindle, I.D.; Lugowska,E. Spectrochim. ActaB.1997, 52, 163-176

25. Dulivio, A.Anal. At. Spectro.1989,4,67-70

26. Niedzielski, P.; Siepak, M.; Siepak, J.; Przybyalek, J. Polish J. Envir. Stud.2002, 11, 219-224

27. Godden, R. G.; Thomerson, D. R. Analyst. 1980,105, 1137-1156

28. Nakahara, T.Progress in Analytical Atomic Spectroscopy. New York, Pergamon Press, 1983

29. Dedina, J. Progress in Analytical Atomic Spectroscopy. New York, Pergamon

\section{Press 1988}

30. Rajan, K.; Roppolo, I.; Chiappone, A.; Bocchini, S.; Perrone, D.; Chiolerio, A. Nanotechnol. Sci. Appl.2016, 9, 1-13

31. Leelavathi, A.; Rao, T.U.B.; Pradeep, T. Nanoscale Res. Lett.2011, 6, 123-132

32. Sharma, V.K.;Yngard, R.A.; Lin, Y. Adv. Colloid Interf. Sci.2009, 145, 83-96

33. Thakur, M.; Pandey, S.; Mewada, A.; Shah, R.; Oza, G.; Sharon, M. Spectrochim. Acta Part A Mol. Biomol. Spectro.2013, 109, 344-347.

34. Sohn, E.K.; Johari, S.A.; Kim, T.G.; Kim, E.; Lee, J.H.; Chung, Y.S.; Yu, I.J. Bio. Med. Res. Int.2015, 89, 3049

35. Goa, X.; Lu, Y.; He, S.; Li, X.; Chen, W. Anal. Chim. Acta.2015, 879, 118-125

36. Zielinska, A.; Skwarek, E.; Zaleska, A.; Gazda, M.; Hupka, J. Procedia Chem.2009, 1, 1560-1566

37. Ebdon, L.; Evans, E.; Fisher, H.; Hill, S.J. An introduction to analytical atomic spectrometry. Chichester, John Wiley \& Sons 1998

38. Shoog, D.A.; Holler, F.J.; Nieman, T.A. Principle of instrumental analysis. $5^{\text {th }}$ ed. Philadelphia, Saunders College Publishing, 1998

39. Dedinna, J.;Tsalev, D.L. Hydride gerneration atomic absorption spectrometry. Chichester, John Wiley \& Sons, 1995

40. Trung, D.Q.; Anh, C.X.; Yasaka, Y.; Fujita, M.; Tanaka, M. Anal. Sci.2001, 17, 1219-1222

41. Lobinski, R. Appl. Spectro. 1997, 51,260A$278 \mathrm{~A}$

42. Jackson, B.P.; Miller, W.P. Envir. Sci.Tech. 1999, 33, 270-275

43. Thompson, M.; Pahlavanpour, B.; Walton, S.J.; Kirkbright, G.F. Analyst.1978, 103, 568-579

44. Tao, G.-H.; Sturgeon, R.E. Spectrochim. Acta B.1999, 54,481-48 